\title{
FAKTOR-FAKTOR YANG MEMPENGARUHI FINANCIAL DISTRESS MENGGUNAKAN SURVIVAL ANALYSIS
}

\author{
Aulia Kania Putri, Farida Titik Kristanti \\ Universitas Telkom, Bandung, Indonesia \\ Email: aulia.monicc@gmail.com
}

\begin{abstract}
The aim of this research is to find that liquidity ratio, sales growth, audit committee, institutional ownership, managerial owership, firm size, board of director and independent commissioner can predict the possibility of financial distress. The object of the research conducted on the mining sector and basic industry and chemicals sectors listed in Indonesian Stock Exchange (IDX) 2009-2018 with a total 70 samples. This study uses survival analysis as a method with cox proportion hazard model. This result of this research that liquidity ratio and audit committee have a negative impact on financial dsitress. Meanwhile, sales growth, firm size, institutional ownership, independent commissioner, board of director and managerial ownership does not have impact on financial distress. The implication of this study is that the company is expected to be able to maintain liquidity at a safe level and increase the internal control.
\end{abstract}

Keywords: Good Corporate Governance, Financial Ratios, Financial Distress, Firm Size, Survival Analysis

\section{ABSTRAK}

Tujuan dari penelitian untuk mengetahui apakah rasio likuiditas, sales growth, komite audit, kepemilikan institusional, kepemilikan manajerial, ukuran perusahaan, jumlah dewan direksi dan komisaris independen mampu memprediksi kemungkinan financial distress. Studi ini dilakukan pada perusahaan sektor industri dasar dan kimia dan sektor pertambangan terdaftar pada Bursa Efek Indonesia (BEI) periode 2009-2018, dengan sampel yang digunakan sebanyak 70 perusahaan. Analisis survival digunakan sebagai teknik analisis data dan menggunakan model cox proportion hazard. Hasil penelitian menunjukkan bahwa rasio likuiditas dan komite audit mampu memengaruhi financial distress. Sales growth, ukuran perusahaan, kepemilikan institusional, komisaris independen, dewan direksi dan kepemilikan manajerial tidak berpengaruh pada financial distress. Implikasi dari studi ini diharapkan perusahaan mampu menjaga likuiditas di tingkat yang aman dan meningkatkan pengawasan internal perusahaan.

Kata kunci: Tata Kelola Perusahaan, Rasio Keuangan, Kesulitan Keuangan, Ukuran Perusahaan, Analisis Ketahanan

\section{KETERANGAN ARTIKEL}

Riwayat Artikel: diterima: 10 Maret 2020; direvisi: 1 Juni 2020; disetujui: 16 Juni 2020

Klasifikasi JEL: F65, G30, M42

Cara Mensitasi: Putri, Aulia K. dan Kristanti, Farida T. (2020). Faktor-faktor yang Mempengaruhi Financial Distress Menggunakan Survival Analysis. JIMFE (Jurnal IImiah Manajemen Fakultas Ekonomi), 6(1), 31-42. https://doi.org/10.34203/jimfe.v6i1.2031

Copyright@2020. JIMFE (Jurnal Ilmiah Manajemen Fakultas Ekonomi) Universitas Pakuan

\section{PENDAHULUAN}

Salah satu tujuan sebuah perusahaan adalah menghasilkan laba yang maksimal, namun tidak selamanya perusahaan terus menerus mendapatkan laba yang baik. Terkadang, perusahaan mengalami penurunan kinerja keuangan yang berujung pada kebangkrutan. Kristanti (2019) menjelaskan bahwa penyebab terjadinya financial distress terbagi atas dua, yaitu masalah internal dan masalah eksternal. Penyebab masalah internal adalah ketidakmampuan perusahaan dalam 
mempertahankan kinerja keuangannya, sehingga perusahaan mengalami kerugian (Widarjo dan Setiawan, 2009). Ratna dan Marwati (2018) menyebutkan bahwa turunnya volume penjualan, menurunnya kemampuan perusahaan dalam menghasilkan laba, dan ketergantungan pada utang besar digunakan sebagai tanda-tanda perusahaan sedang berada dalam kondisi financial distress. laba bersih negatif menjadi alat ukur dari financial distress, karena laba negatif menggambarkan perusahaan berada dalam kondisi kesulitan keuangan (financial distress) yang berdampak pada kelangsungan usahanya (Zhafirah dan Majidah, 2019).

Berdasarkan data ICMD, perusahaan yang terdaftar di sektor pertambangan dan sektor industri dasar dan kimia periode 20092018 yang mengalami kerugian berfluktuasi. Tahun 2009, terdapat 16 perusahaan yang mengalami kerugian. Tahun 2010 hingga 2015 mengalami kenaikan jumlah perusahaan yang rugi, di mana tahun 2015 sebanyak 39 perusahaan yang mengalami kerugian. Tahun 2016 hingga 2018 mengalami penurunan dalam jumlah perusahaan yang mengalami kerugian, namun kerugian tersebut tidak serendah dari tahun 2009 hingga 2014. Hal tersebut mengindikasikan bahwa masih banyak perusahaan sektor pertambangan dan sektor industri dasar dan kimia berada posisi financial distress.

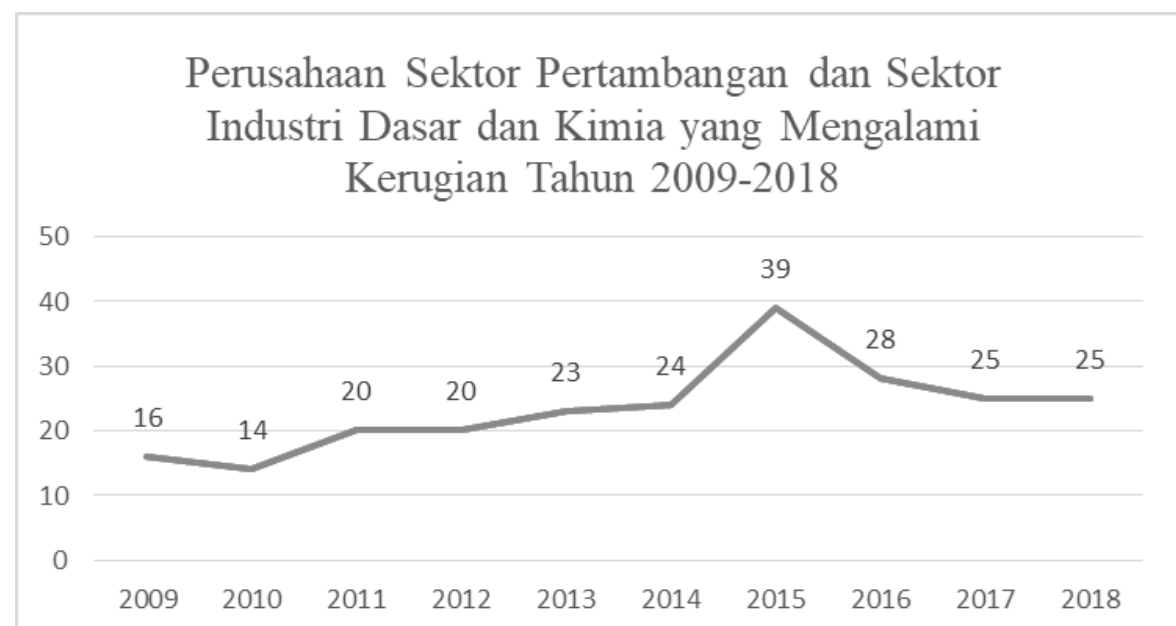

Gambar 1. Jumlah Perusahaan yang Mengalami Kerugian Tahun 2009-2018

Sumber: data diolah, 2020

Hasil penelitian terdahulu menunjukkan inkonsistensi pada setiap variabelnya. Penelitian Triwahyuningtias dan Muharam (2012) menunjukkan likuiditas memiliki pengaruh positif pada financial distress. Penelitian Cinantya dan Merkusiwati (2015) memiliki hasil yang berbeda, financial distress tidak mampu dipengaruhi oleh likuiditas.

Hasil studi Widhiari dan Merkusiwati (2015) sales growth memiliki pengaruh pada terjadinya financial distress. Penelitian Muflihah (2017) menunjukkan sales growth tidak berpengaruh pada financial distress. Riset Ningrum dan Hatane (2017), ukuran perusahaan berpengaruh dengan arah positif pada terjadinya financial distress. Riset yang dilakukan Sastriana dan Fuad (2013) menunjukkan ukuran perusahaan tidak memengaruhi kemungkinan terjadinya kondisi kesulitan keaungan.

Sastriana dan Fuad (2013) menunjukkan kepemilikan institusional tidak memengaruhi financial distress, penelitian Triwahyuningtias dan Muharam (2012) menunjukkan hasil yang 
berbeda, kepemilikan institusional berpengaruh negatif pada financial distress. Penelitian Triwahyuningtias dan Muharam (2012) kepemilikan manajerial memiliki pengaruh arah positif tehadap financial distress. Sedangkan Cinantya dan Merkusiwati (2015) menjelaskan bahwa financial distress tidak dipengaruhi oleh kepemilikan manajerial.

Komisaris independen dalam penelitian Helena dan Saifi (2018), menghasilkan financial distress dipengaruhi oleh komisaris independen. Namun, berbeda dengan Sastriana Fuad (2013), karena komisaris independen tidak dapat memengaruhi financial distress. Penelitian Helena dan Saifi (2018) menghasilkan financial distress tidak dapat dipengaruhi oleh komite audit. Riset tersebut berbeda dengan Ariesta dan Chariri (2013), kondisi financial distress dipengaruhi oleh komite audit. Helena dan Saifi (2018) menyebutkan bahwa dewan direksi mampu memengaruhi kondisi financial distress perusahaan. Tidak senada dengan Cinantya dan Merkusiwati (2015), yang menghasilkan financial distress tidak dpengaruhi dewan direksi.

Kebaruan dalam penelitian ini adalah teknik analisis data yang digunakan survival analysis. Teknik ini masih jarang digunakan untuk memprediksi financial distress.

\section{KAJIAN LITERATUR DAN PENGEMBANGAN HIPOTESIS}

\section{Agency Theory}

Agency theory membahas ikatan kontrak antara principals (pemilik saham) dengan agent (manajemen). Agent melakukan layanan jasa atas nama principals. Principals memberikan perintah kepada agent, sedangkan agent diberikan amanah untuk menjalankan perusahaan. Hubungan keagenan selalu menimbulkan permasalahan antara agent dan principals karena perbedaan pola pikir dan kepentingan.

\section{Signaling Theory}

Menurut Lo (2012) teori signaling dijelaskan sebagai pemberian sinyal kepada pasar mengenai kondisi keuangan perusahaan. Spence (1973) menjelaskan sinyal dikirimkan kepada pihak eksternal dikarenakan perusahaan memiliki kinerja keuangan yang cukup baik. Perusahaan yang mengirimkan sinyal buruk kepada pihak eksternal mengeluarkan biaya lebih tinggi daripada perusahaan yang mengirimkan sinyal baik.

\section{Financial Distress}

Ratna dan Marwati (2018) berpendapat bahwa financial distress terjadi tepat sebelum perusahaan bangkrut. Salah satu tanda perusahaan berada dalam kondisi financial distress salah satunya adalah penurunan laba terus menerus hingga mengalami kerugian. Menurut Patunrui dan Yati (2017) financial distress adalah sebuah keadaan perusahaan yang kinerja keuangannya mengalami penurunan dan tidak likuid yang apabila tidak segera ditangani dapat menyebababkan kebangkrutan. Menurut Kristanti dan Herwany (2017), umumnya terdapat empat karakteristik perusahaan yang gagal, yaitu failure (kelalaian), insolvency (tidak mampu membayar utang), default (kegagalan) dan bankruptcy (kebangkrutan).

\section{Rasio Likuiditas}

Rasio keuangan menunjukkan kemampuan perusahaan seberapa jauh perusahaan dapat membiayai kewajiban janga pendeknya dengan aset lancarnya sebelum jatuh tempo (Triwahyuningtias dan Muharam, 2012). Current ratio menjadi alat ukur dari rasio likuiditas. Perusahaan dengan tingkat likuiditas yang tinggi, akan tinggi pula kemampuan membayar utang lancarnya sebelum jatuh tempo dan terhindar dari kondisi financial distress. Hal ini didukung oleh beberapa peneliti, yaitu Susilowati dan Fadlillah (2019), Widhiari dan Merkusiwati (2015), dan Cinantya dan Merkusiwati (2015). 


\section{Sales Growth}

Sales growth menggambarkan pertumbuhan penjualan, pertumbuhan yang tinggi, maka akan semakin tinggi pula kapasitas operasi perusahaan (Aprianto dan Dwimulyani, 2019). Menurut Rakasiwi, dkk. (2017) sales growth merupakan kemampuan perusahaan mempertahankan daya saing dalam suatu industri. Tingginya sales growth, akan semakin besar pula peluang perusahaan memiliki profit yang didapatkan, perusahaan pun mampu mempertahankan kelangsungan usahanya dan kemungkinan terjadinya financial distress pun rendah. Artinya, pertumbuhan sales growth memiliki hubungan negatif dengan financial distress. Hal ini didukung hasil riset dari Yudiawati dan Indriani (2016) dan Widhiari dan Merkusiwati (2015).

\section{Ukuran Perusahaan}

Suwardika dan Mustanda (2017) firm size menjelaskan bahwa ukuran besar atau kecilnya sebuah perusahaan, firm size diukur dengan total aset. Firm size memiliki empat macam ukuran perusahaan diukur dengan kekayaan bersih dan jumlah penjualannya, yaitu perusahaan dengan usaha mikro, perusahaan dengan usaha kecil, perusahaan dengan usaha menengah dan usaha dengan usaha besar. Ukuran perusahaan yang semakin besar, besar pula aset yang dimiliki perusahaan, dengan aset yang besar, perusahaan dapat melakukan diversifikasi, potensi perusahaan mendapatkan laba pun besar dan kemungkinan terjadinya financial distress pun kecil. Hal ini didukung oleh hasil penelitian Kristanti dan Herwany (2017) dan Putri dan Merkusiwati (2014).

\section{Kepemilikan Institusional}

Sastriana dan Fuad (2013) menjelaskan bahwa kepemilikan institusional merupakan pihak institusi (bank, asuransi, dana pensiun, reksa dana, yayasan, dan lainnya) yang memiliki saham pada perusahaan tersebut. Besarnya kepemilikan pihak institusi dapat memotivasi aktivitas monitoring oleh pihak institusi terhadap manajemen perusahaan dan akan memengaruhi pengambilan keputusan. Monitoring yang dilakukan bertujuan agar pengambilan keputusan lebih berpihak kepada pemegang saham, dan peluang perusahaan mengalami financial distress berkurang. Disimpulkan, variabel ini memiliki hubungan negatif dengan financial distress. Hal ini dari riset yang dilakukan oleh Helena dan Saifi (2018), Cinantya dan Merkusiwati (2015).

\section{Kepemilikan Manajerial}

Miraza dan Muniruddin (2017) menjelaskan manajemen yang memiliki saham diperusahaannya merupakan kepemilikan manajerial, struktur kepemilikan ini dipercaya mampu untuk memengaruhi keputusan pendanaan. Kepemilikan saham oleh pihak manajemen mampu mengurangi masalah keagenan, peninkatan kinerja manajemen, dan mengurangi kecurangan yang dapat merugikan perusahaan. Berdasarkan hipotesis yang dibangun, kepemilikan manajerial memiliki hubungan negatif pada peluang mengalami financial distress. Hal ini senada dengan riset Khairuddin, dkk. (2019) dan Hanafi dan Breliastiti (2016).

\section{Komisaris Independen}

Menurut Fathonah (2016) komisaris independen merupakan bagian dari anggota dewan komisaris yang tidak terikat denga organ-organ perusahaan dan bebas dari hubungan bisnis. Komisaris independen berfungsi untuk mnegawasi kinerja dewan direksi dan bertindak secara independen (Radifan dan Yuyetta, 2015). Perusahaan yang memiliki banyak anggota komisaris independen, mengindikasikan bahwa tata kelola perusahaan baik, diharapkan kinerja keuangannya pun baik, dan kecil kemungkinan terjadinya financial distress. Agency theory (teori keagenan) menjelaskan perusahaan dengan dewan komisaris independen yang banyak mampu mengawasi pihak manajemen dari tindakan oportunistik yang dapat 
merugikan perusahaan. serupa dengan riset yang dilakukan oleh Kristanti dan Herwany (2017) dan Fathonah (2016).

\section{Komite Audit}

Damayanti dan Susanto (2015) menjelaskan komite audit merupakan organ perusahaan berjumlah paling sedikit tiga orang, dibentuk oleh dewan komisaris. Komite audit bertugas melakukan monitoring atas internal perusahaan atas pelaksanaan audit, asas-asas corporate governance, maupun manajemen risiko (Irma, 2019). Ukuran komite audit yang tinggi akan menaikkan kinerja komite audit, dikarenakan perusahaan yang memiliki anggota komite audit yang besar mampu membenahi urusan yang terjadi di perusahaan seperti kecurangan yang dapat mengalami kerugian, kecil kemungkinan perusahaan mengalami kondisi financial distress. Hal ini senada dengan riset Masak dan Noviyanti (2019) dan Munawar, dkk. (2018).

\section{Dewan Direksi}

Khairuddin, dkk. (2019) menjelaskan bahwa dewan direksi adalah organ perusahaan yang memimpin kegiatan operasi perusahaan. Radifan dan Yuyetta (2015) menjelaskan dewan direksi merupakan seorang agent yang bertugas menjalankan perintah yang diberikan oleh principals (pemegang saham). Masingmasing dewan direksi, mempunyai tugas masing-masing dan mempunyai hak untuk mengambil keputusan sehubungan dengan kegiatan operasi perusahaan. Ukuran dewan direksi yang besar dapat memperkuat monitoring internal perusahaan, mampu menaikkan kinerja perusahaan dan mengurangi peluang terjadinya financial distress atau kerugian. Didukung beberapa peneliti, yaitu Helena dan Saifi (2018) dan Hanafi dan Breliastiti (2016).

Dari hal di atas, maka dapat dibangun hipotesis penelitian sebagai pernyataan sementara dari penelitian ini, yaitu sebagai berikut:

H1: Rasio ikuiditas dapat memprediksi financial distress dengan arah negatif

$\mathrm{H} 2$ : Sales growth dapat memprediksi financial distress dengan arah negatif

H3: Ukuran perusahaan dapat memprediksi financial distress dengan arah negatif.

H4: Kepemilikan institusional dapat memprediksi financial distress dengan arah negatif.

H5: Kepemilikan manajerial dapat memprediksi financial distress dengan arah negatif.

H6: Komisaris independen dapat memprediksi financial distress dengan arah negatif.

H7: Komite audit dapat memprediksi financial distress dengan arah negatif.

H8: Dewan direksi dapat memprediksi financial distress dengan arah negatif. 


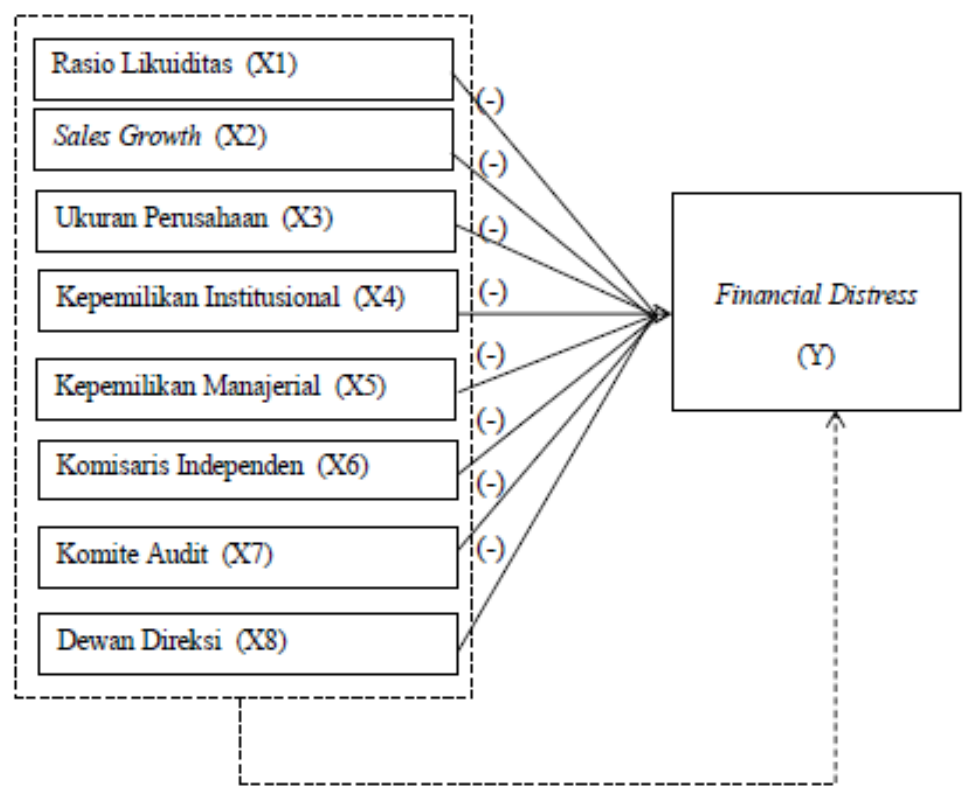

Gambar 2. Kerangka Pemikiran

Sumber: data diolah, 2020

\section{METODE PENELITIAN}

Metode yang digunakan kuantitatif. Berdasarkan tujuan penelitian, penelitian ini tergolong dalam jenis deskriptif. Waktu pelaksanaan menggunakan data panel, adalah campuran time series dengan cross section. Purposive sampling menjadi teknik pengambilan sampel dengan kriteria perusahaan industri dasar dan kimia dan perusahaan pertambangan di BEI periode 2009-2018, perusahaan yang konsisten menerbitkan laporan keuangan tahunan di BEI tahun 2009-2018, perusahaan yang mempunyai data keuangan yang lengkap, sehingga diperoleh 70 perusahaan dengan waktu penelitian 10 tahun. Alat uji yang digunakan adalah SPSS 23. 
Tabel 1. Operasionalisasi Variabel

\begin{tabular}{|c|c|c|}
\hline Variabel & Indikator & Skala \\
\hline $\begin{array}{l}\text { Financial } \\
\text { Distress (Y) }\end{array}$ & $\begin{array}{l}\text { Laba negatif nilai } 1 \\
\text { Laba positif nilai } 0\end{array}$ & Dummy \\
\hline $\begin{array}{l}\text { Rasio Likuiditas } \\
\text { (X1) }\end{array}$ & Current Ratio $=\frac{\text { Aset Lancar }}{\text { Utang Lancar }}$ & Rasio \\
\hline $\begin{array}{l}\text { Sales Growth } \\
(\mathrm{X} 2)\end{array}$ & Sales Growth $=\frac{\left(\text { penjualan }_{t}-\text { penjualan }_{t-1}\right)}{\text { penjualan }_{t-1}}$ & Rasio \\
\hline $\begin{array}{l}\text { Ukuran } \\
\text { Perusahaan } \\
\text { (X3) }\end{array}$ & Ukuran Perusahaan $=\operatorname{Ln}($ total aset $)$ & Rasio \\
\hline $\begin{array}{l}\text { Kepemilikan } \\
\text { Institusional } \\
\text { (X4) }\end{array}$ & $\begin{array}{l}\text { Kepemilikan Institusional } \\
\qquad=\frac{\text { Saham Institusional }}{\text { Saham yang beredar }}\end{array}$ & Rasio \\
\hline $\begin{array}{l}\text { Kepemilikan } \\
\text { Manajerial (X5) }\end{array}$ & $\begin{array}{l}\text { Kepemilikan Manajerial } \\
\qquad=\frac{\text { Saham manajerial }}{\text { Saham yang beredar }}\end{array}$ & Rasio \\
\hline $\begin{array}{l}\text { Komisaris } \\
\text { Independen } \\
\text { (X6) }\end{array}$ & $\begin{array}{l}\text { Komisaris Independen } \\
\qquad=\frac{\text { Komisaris independen }}{\text { Dewan komisaris }}\end{array}$ & Rasio \\
\hline $\begin{array}{l}\text { Komite Audit } \\
\text { (X7) }\end{array}$ & Komite Audit $=\sum$ Komite audit (7) & Nominal \\
\hline $\begin{array}{l}\text { Dewan Direksi } \\
\text { (X8) }\end{array}$ & Jumlah dewan direksi $=\sum$ Dewan direksi (8) & Nominal \\
\hline
\end{tabular}

Sumber: data diolah, 2020

\section{Teknik Analisis Data}

Kuantitatif digunakan sebagai metode penelitian, teknik perhitungan menggunakan statistik deskriptif. Teknik analisis data menggunakan analisis survival. Analisis survival menurut Kristanti dan Herwany (2017) teknik analisis yang digunakan untuk menentukan kemampuan seperti tata kelola perusahaan, risiko keuangan perusahaan yang gagal bertahan. Analisis ini mempelajari model statistik untuk mempelajari kasus dan waktu dari suatu peristiwa. Kristanti dan Isynuwardhana (2018) menjelaskan bahwa model cox proportion hazard yang digunanakan untuk menganalisis variabel yang digunakan dalam menilai financial distress, karena teknik analisis survival lebih konsisten dan akurat daripada teknik analisis lainnya.

$$
\begin{gathered}
h i(t)=H_{0}(t) \exp \left[\beta_{1} L I Q+\beta_{2} S G R O W T H+\beta_{3} S I Z E+\beta_{4} I N S O W N+\beta_{5} M A N O W N\right. \\
\left.+\beta_{6} I N D C O M+\beta_{7} \text { ACSIZE }+\beta_{8} D I R S I Z E\right]
\end{gathered}
$$

Di mana:

hi(t) = hazard perusahaan dalam financial distress pada t waktu

$L I Q=$ Rasio Likuiditas
SGROWTH = Pertumbuhan Penjualan

SIZE = Ukuran Perusahaan

INSOWN = Kepemilikan Institusional

MANOWN = Kepemilikan Manajerial 
INDCOM = Komisaris Independen

ACSIZE = Komite Audit

DIRSIZE = Dewan Direksi

HASIL DAN PEMBAHASAN

Uji Statistik Deskriptif

Tabel 2 menjelaskan bahwa ukuran perusahaan, kepimilikan institusional, komisaris independen, dan dewan direksi memiliki standar deviasi yang rendah dari rata-rata yang artinya data relatif tidak beragam. Sedangkan, untuk variabel rasio likuiditas, sales growth, kepemilikan manajerial dan komite audit mempunyai ratarata yang rendah dari standar deviasi artinya data bervariasi dan menyebar di sekitar ratarata.

Tabel 2. Statistik Deskriptif

\begin{tabular}{lccccc}
\hline & $\mathrm{N}$ & Min & Max & Mean & Std.Dev \\
\hline Liq & 70 & 0,347 & 24,56 & 2,11 & 2,98 \\
\hline SGrowth & 70 & $-0,959$ & 0,733 & 0,017 & 0,263 \\
\hline Size & 70 & 22,66 & 32,26 & 28,64 & 2,02 \\
\hline InsOwn & 70 & 0,101 & 0,969 & 0,651 & 0,214 \\
\hline ManOwn & 70 & 0,000 & 0,650 & 0,045 & 0,119 \\
\hline IndCom & 70 & 0,000 & 0,60 & 0,360 & 0,108 \\
\hline ACSize & 70 & 0,0 & 5,0 & 2,80 & 1,09 \\
\hline DirSize & 70 & 2,0 & 11,0 & 4,96 & 2,18 \\
\hline
\end{tabular}

Sumber: data primer yang diolah, 2020

\section{Omnibus Test of Model Coefficient}

Bertujuan untuk mengetahui nilai signifikansi model keseluruhan. Nilai signifikan sebesar $5 \%$. Berguna untuk memeriksa apakah model yang digunakan fit atau sesuai. Berdasarkan tabel 3, hasil signifikan pada tingkat overall
$0,001<0,05$, menjelaskan bahwa variabel terikat bisa dijelaskan oleh variabel bebasnya. Hal ini menunjukkan model yang digunakan sesuai.

Tabel 3. Tabel Omnibus Test of Model Coefficient

\begin{tabular}{ccccccccccc}
\hline \multirow{2}{*}{$\begin{array}{c}-2 \text { Log } \\
\text { Likehood }\end{array}$} & \multicolumn{3}{c}{ Overall (Score) } & \multicolumn{4}{c}{$\begin{array}{c}\text { Change from Previous } \\
\text { Step }\end{array}$} & \multicolumn{4}{c}{$\begin{array}{c}\text { Change from Previous } \\
\text { Block }\end{array}$} \\
\cline { 2 - 12 } & Chi-square & df & Sig. & Chi-square & df & Sig & Chi-square & df & Sig. \\
\hline 341,161 & 25,755 & 8 & 0,001 & 28,068 & 8 & 0,000 & 28,068 & 8 & 0,000 \\
\hline
\end{tabular}

Sumber: data primer yang diolah, 2020

Uji Model Cox Proportion Hazard

Tabel 4. Uji Cox Proportional Hazard

\begin{tabular}{lcccccc}
\hline & B & SE & Wald & df & Sig. & Exp(B) \\
\hline Liq & $-0,448$ & 0,162 & 7,342 & 1 & 0,007 & 0,639 \\
\hline SGrowth & $-0,361$ & 0,561 & 0,414 & 1 & 0,520 & 0,697 \\
\hline Size & $-0,093$ & 0,102 & 0,832 & 1 & 0,362 & 0,911 \\
\hline InsOwn & 0,164 & 0,888 & 0,034 & 1 & 0,853 & 1,179 \\
\hline ManOwn & $-0,542$ & 1,756 & 0,095 & 1 & 0,757 & 0,581 \\
\hline IndCom & 1,522 & 1,565 & 0,946 & 1 & 0,331 & 4,580 \\
\hline ACSize & $-0,466$ & 0,169 & 7,604 & 1 & 0,006 & 0,627 \\
\hline
\end{tabular}




\begin{tabular}{lllllll}
\hline DirSize & 0,006 & 0,079 & 0,006 & 1 & 0,936 & 1,006 \\
\hline
\end{tabular}

Sumber: data primer yang diolah, 2020

Likuiditas memiliki signifikansi 0,007 di mana lebih rendah daripada tingkat signifikansi 5\%, dan nilai koefisien senilai 0,448 . Artinya, likuiditas memiliki pengaruh negatif terhadap financial distress. Likuiditas yang rendah akan mengakibatkan perusahaan kesulitan membayar utang lancarnya dan dapat menyebabkan financal distress. Hasil ini mendukung riset Susilowati dan Fadlillah (2019), Widhiari dan Merkusiwati (2015) dan Cinantya dan Merkusiwati (2015).

Sales growth dengan tingkat signifikan $0,520>0,05$, koefisien sebesar $-0,361$. Ukuran perusahaan tidak dapat memengaruhi kemungkinan terjadinya financial distress. Meskipun tingkat pertumbuhan penjualan yang dimiliki perusahaan rendah, perusahaan masih mampu membayar beban-bebannya dan mampu menghasilkan laba. Hasil ini mendukung penelitian Muflihah (2017) dan Istiantoro dan Indrawati (2015) menjelaskan sales growth tidak mampu memengaruhi financial distress. Hasil ini bertolak belakang dengan riset Yudiawati dan Indriani (2016) dan Widhiari dan Merkusiwati (2015) di mana menjelaskan jika pertumbuhan memiliki dampak pada financial distress.

Ukuran perusahaan $\left(\mathrm{H}_{3}\right)$ tidak mampu memengaruhi terjadinya financial distress, ukuran perusahaan mempunyai tingkat signifikan 0,362>0,05 dengan koefisien -0,093. Dijelaskan bahwa besar atau kecilnya perusahaan sudah memiliki kinerja baik dan terhindar dari financial distress. Senada dengan riset Cinantya dan Merkusiwati (2015) dan Sastriana dan Fuad (2013) bertolak belakang dengan penelitian Kristanti dan Herwany (2017), Kristanti dan Effendi (2017) dan Putri dan Merkusiwati (2014) yang menyebutkan bahwa kondisi financial distress mampu dipengaruhi oleh firm size.

Hipotesis keempat $\left(\mathrm{H}_{4}\right)$ memiliki hasil pengujian, financial distress tidak dipengaruhi oleh kepemilikan institusional memiliki tingkat signifikan $0,853>0,05$. Sastriana dan Fuad (2013) menjelaskan, pihak institusi selaku pemegang saham tidak mampu mengendalikan manajemen, kemungkinan dalam pengambilan keputusan manajemen hanya menguntungkan dirinya sendiri. Hasil ini menolak penelitian Helena dan Saifi (2018), Cinantya dan Merkusiwati (2015) dan Radifan dan Yuyetta (2015).

Kepemilikan manajerial dalam hipotesis kelima $\left(\mathrm{H}_{5}\right)$ menghasilkan nilai signifikan $0,757>0,05$. Kepemilikan manajerial tidak dapat memengaruhi financial distress. Sastriana dan Fuad (2013) menjelaskan kepemilikan manajerial hanya untuk pancingan kepada investor karena apabila pihak manajemen memiliki saham padah perusahaannya maka tidak terjadi masalah keagenan dan pihak manajemen dapat memaksimalkan profit. Hasil ini tidak senada dengan Triwahyuningtias dan Muharam (2012)

Hipotesis keenam $\left(\mathrm{H}_{6}\right)$ yaitu komisaris independen tidak mampu memengaruhi financial distress, komisaris independen memiliki signifikansi sebesar 0,331>0,05. Hasil ini mendukung dari riset Triwahyuningtias dan Muharam (2012), Helena dan Saifi (2018), dan Cinantya dan Merkusiwati (2015). Menurut Sastriana dan Fuad (2013), adanya komisaris independen hanya formalitas saja untuk mengikuti regulasi yang ada. Namun hasil ini bertolak belakang dengan riset Farida Titik Kristanti dan Herwany (2017) dan Fathonah (2016).

Hipotesis ketujuh $\left(\mathrm{H}_{7}\right)$ yaitu komite audit dengan sig. $0,006<0,05$, koefisien sebesar -0,466. Artinya, kondisi financial distress mampu dipengaruhi oleh komite audit. Ukuran komite audit yang tinggi mampu menaikkan efektivitas kinerjanya untuk menangani masalah-masalah internal perusahaan yang mampu menyebabkan 
kerugian. Hasil ini mendukung riset Masak dan Noviyanti (2019) dan Munawar dkk., (2018).

Hipotesis kedelapan $\left(\mathrm{H}_{8}\right)$ yaitu dewan direksi memiliki hasil nilai signifikansi 0,936> 0,05 . Artinya, dewan direksi tidak dapat memengaruhi financial distress. Hasil dari penelitian ini senada dengan riset Cinantya dan Merkusiwati (2015) yang mengatakan meskipun beberapa dewan direksi memiliki hak dan wewenang, namun pada saat dilaksanakan RUPS, keputusan baru diambil, sehingga beberapa anggota dewan direksi tidak memengaruhi kemungkinan financial distress.

\section{PENUTUP}

Berdasarkan pembahasan, dapat disimpulkan variabel independen rasio likuiditas yang diproksikan current ratio dan ukuran komite audit memiliki pengaruh signifikan dengan arah negatif terhadap kemungkinan financial distress. di mana semakin tinggi likuiditas dan semakin banyak anggota komite audit dapat mengurangi kemungkinan financial distress. Namun, sales growth, komisaris independen, kepemilikan institusional, dewan direksi, firm size dan kepemilikan manajerial tidak dapat memengaruhi financial distress.

Implikasi dari studi ini diharapkan perusahaan mampu mempertahankan kelangsungan usahanya dengan cara menjaga likuiditas perusahaan di tingkat yang aman dan meningkatkan pengawasan internal perusahaan agar terhidar dari kemungkinan terjadinya financial distress yang dapat mengakibatkan kebangkrutan.

Saran untuk peneliti selanjutnya yaitu, menambahkan variabel-variabel yang dapat memengaruhi kemungkinan terjadinya financial distress seperti rasio keuangan yang lainnya, inflasi dan variabel lainnya.

\section{REFERENSI}

Aprianto, M., \& Dwimulyani, S. (2019). Pengaruh Sales Growth dan Leverage terhadap Tax Avoidance dengan Kepemilikan Institusional Sebagai
Variabel Moderasi. Prosiding Seminar Nasional Pakar, 2, 1-10.

Ariesta, D. R., \& Chariri, A. (2013). Analisis Pengaruh Struktur Dewan Komisaris, Struktur Kepemilikan Saham dan Komite Audit terhadap Financial Distress. Diponegoro Journal of Accounting, 1(1), 1-9.

Cinantya, I., \& Merkusiwati, N. (2015). Pengaruh Corporate Governance, Financial Indicators, dan Ukuran Perusahaan pada Financial Distress. EJurnal Akuntansi, 10(3), 897-915.

Damayanti, F., \& Susanto, T. (2015). Pengaruh Komite Audit, Kualitas Audit, Kepemilikan Institusional, Risiko Perusahaan dan Return on Assets terhadap Tax Avoidance. Jurnal Bisnis Dan Manajemen, 5(2), 187-206.

Fathonah, A. N. (2016). Pengaruh Penerapan Good Corporate Governance terhadap Financial Distress. Jurnal Ilmiah Akuntansi, 1(2), 133-150.

Hanafi, J., \& Breliastiti, R. (2016). Peran Mekanisme Good Corporate Governance dalam Mencegah Perusahaan Mengalami Financial Distress. Jurnal Online Insan Akuntan, 1(1), 195-220.

Helena, S., \& Saifi, M. (2018). Pengaruh Corporate Governance terhadap Financial Distress (Studi pada Perusahaan Transportasi yang Terdaftar di Bursa Efek Indonesia Periode 2013-2016). Jurnal Administrasi Bisnis, 60(2), 143-152.

Irma, A. D. A. (2019). Pengaruh komisaris, komite audit, struktur kepemilikan, size dan leverage terhadap kinerja keuangan perusahaan properti, perumahan dan konstruksi 2013-2017. Jurnal IImu Manajemen (JIM), 7(3), 697-712.

Istiantoro, J. N., \& Indrawati, N. K. (2015). Pengaruh Rasio Keuangan terhadap Kondisi Financial Distress (Studi pada Perusahaan Tekstil dan Garmen yang Terdaftar di BEI). Jurnal IImiah Mahasisa FEB, 3(2), 1-13.

Khairuddin, F., Mahsuni, A. W., \& Afifudin. 
(2019). Pengaruh Good Corporate Governance dan Rasio Likuiditas terhadap Financial Distress Diperusahaan Manufaktur yang Terdaftar di Bei 20152018. E-Jurnal Riset Akuntansi, 08(01), 142-158.

Kristanti, F. T., \& Effendi, N. (2017). A Survival Analysis of Indonesian Distressed Company Using Cox Hazard Model. International Journal of Economics and Management, 11(S1), 157-169.

Kristanti, Farida Titik. (2019). Financial Distress (Teori dan Perkembangan Dalam Konteks Indonesia). Malang: Intelegensia Media.

Kristanti, Farida Titik, \& Herwany, A. (2017). Corporate Governance, Financial Ratios, Political Risk and Financial Distress: A Survival Analysis. Accounting \& Finance

Kristanti, Farida Titik, \& Isynuwardhana, D. (2018). How long are The Survival Time in the Industrial Sector of Indonesian Companies? International Journal of Engineering \& Technology, 7(4.38), 856860.

Lo, E. W. (2012). Pengaruh Tingkat Kesulitan Keuangan terhadap Manajemen Laba: Teori Keagenan versus Teori Signaling. Jurnal Riset Akuntansi Dan Keuangan, 8(1), 1-18.

Masak, F., \& Noviyanti, S. (2019). Pengaruh Karakteristik Komite Audit terhadap Financial Distress. International Journal of Social Science and Business, 3(3), 237247.

Miraza, C. N., \& Muniruddin, S. (2017). Pengaruh Kepemilikan Institusional, Kepemilikan Manajerial, Variabilitas Pendapatan, Corporate Tax Rate, dan Non Debt Tax Shield terhadap Struktur Modal pada Perusahaan Manufaktur yang Terdaftar di Bei Tahun 2011-2015. Jurnal Ilmiah Mahasiswa Ekonomi Akuntansi (JIMEKA), 2(3), 73-85.

Muflihah, I. Z. (2017). Analisis Financial Distress Perusahaan Manufaktur di Indonesia dengan Regresi Logistik.
Majalah Ekonomi, XXII(2), 254-269.

Munawar, I., Firli, A., \& Iradianty, A. (2018). Pengaruh Good Corporate Governance terhadap Financial Distress (Studi pada Perusahaan Subsektor Tekstil dan Garmen di Bursa Efek Indonesia Tahun 2012-2016). E-Proceeding of Management, 5(2), 1867-1877.

Ningrum, A., \& Hatane, S. E. (2017). Pengaruh Corporate Governance terhadap Financial Distress. Business Accounting Review, 5(1), 241-252.

Patunrui, K. I. A., \& Yati, S. (2017). Analisis Penilaian Financial Distress Menggunakan Model Altman (Z- Score) pada Perusahaan Farmasi yang Terdaftar di Bursa Efek Indonesia Periode 20132015. Jurnal Akuntansi, Ekonomi Dan Manajemen Bisnis, 5(1), 55-71.

Putri, N. W. K. A., \& Merkusiwati, N. K. L. A. (2014). Pengaruh Mekanisme Corporate Governance, Likuiditas, Leverage, dan Ukuran Perusahaan pada Financial Distress. E-Jurnal Akuntansi, 7(1), 93106.

Radifan, R., \& Yuyetta, E. N. A. (2015). Analisis Pengaruh Mekanisme Good Corporate Governance Terhadap Kemungkinan Financial Distress. Diponegoro Journal of Accounting, 4(3), 1-11.

Rakasiwi, F. W., Pranaditya, A., \& Andini, R. (2017). Pengaruh EPS, Ukuran Perusahaan, Profitabilitas, Leverage, Sales Growth dan Kebijakan Dividen terhadap Nilai Perusahaan pada Industri Makanan dan Minuman yang Terdaftar di Bursa Efek Indonesia Tahun 2010-2015. Journal of Accounting, 3(3), 1-15.

Ratna, I., \& Marwati. (2018). Analisis FaktorFaktor yang Mempengaruhi Kondisi Financial Distress pada Perusahaan yang Delisting Dari Jakarta Islamic Index Tahun 2012-2016. Jurnal Tabarru': Islamic Banking and Finance, 1(1), 51-62.

Sastriana, D., \& Fuad. (2013). Pengaruh Corporate Governance dan Firm Size 
terhadap Perusahaan yang Mengalami Kesulitan Keuangan (Financial Distress). Diponegoro Journal of Accounting, 2(3), 1-10.

Spence, M. (1973). Job Market Signaling. The Quarterly Journal of Economics, 87(3), 355-374.

Susilowati, P. I. M., \& Fadlillah, M. R. (2019). Faktor-Faktor yang Mempengaruhi Financial Distress pada Perusahaan Manufaktur di Indonesia. Jurnal AKSI (Akuntansi Dan Sistem Informasi), 4(1), 19-28.

Suwardika, I. N. A., \& Mustanda, I. K. (2017). Pengaruh Leverage, Ukuran Perusahaan, Pertumbuhan Perusahaan, dan Profitabilitas terhadap Nilai Perusahaan pada Perusahaan Properti. E-Jurnal Manajemen Universitas Udayana, 6(3), 1248-1277.

Triwahyuningtias, M., \& Muharam, H. (2012). Analisis Pengaruh Struktur Kepemilikan, Ukuran Dewan, Komisaris Independen, Likuiditas dan Leverage terhadap Terjadinya Kondisi Financial Distress (Studi pada Perusahaan Manufaktur yang Terdaftar di Bursa Efek Indonesia Tahun
2008-2010). Diponegoro Journal of Management, 1(1), 1-14.

Widarjo, W., \& Setiawan, D. (2009). Pengaruh Rasio Keuangan terhadap Kondisi Financial Distress Perusahaan Otomotif. Jurnal Bisnis Dan Akuntansi, 11(2), 107119.

Widhiari, N. L. M. A., \& Merkusiwati, N. K. L. A. (2015). Pengaruh Rasio Likuiditas, Leverage, Operating Capacity, dan Sales Growth terhadap Financial Distress. EJurnal Akuntansi, 11(2), 456-469.

Yudiawati, R., \& Indriani, A. (2016). Analisis Pengaruh Current Ratio, Debt to Total Asset Ratio, Total Asset Turnover, dan Sales Growth Ratio terhadap Kondisi Financial Distress (Studi Kasus pada Perusahaan Manufaktur yang Terdaftar di BEI Tahun 2012-2014). Diponegoro Journal Of Management, 5(2), 1-13.

Zhafirah, A., \& Majidah. (2019). Analisis Determinan Financial Distress (Studi Empiris pada Perusahaan Subsektor Tekstil dan Garmen Periode 2013-1017). Jurnal Riset Akuntansi Dan Keuangan, 7(1), 195-202. 